\title{
ANÁLISIS ACTUAL DEL MERCADO INMOBILIARIO ANTE UNA NUEVA LEY DE VIVIENDA
}

\author{
Juan Carlos Gamazo Chillón
}

Departamento de Economía Aplicada

E-mail: gamazo@der.uva.es

\begin{abstract}
RESUMEN: En el presente trabajo se analiza como la crisis sanitaria generada por el Covid-19 ha influido en el acceso a la vivienda para una familia media española. Con este objetivo se estudia en primer lugar los efectos de la pandemia sobre la economía en general y el sector inmobiliario en particular, para después centrarse en las consecuencias del coronavirus sobre los principales indicadores de la demanda y de la oferta del mercado de la vivienda: compraventa, hipotecas, consumo de cemento, etc. Finalmente, se proponen una serie de medidas tendentes a facilitar el acceso a la vivienda.

Palabras clave: Vivienda, pandemia, acceso a la vivienda, precios e hipotecas.

ABSTRACT: This work analyses the effects of health crisis generated by the Covid-19 on the access to housing for a Spanish average household. Following this objective, the impact of pandemic on the economy, in general, and on housing sector, in particular, are highlighted at the beginning of the research. Then this paper focus on the main components of the demand and supply of the housing market (buying and selling homes, mortgages, cement consumption, etc.). It finishes with a final reflection about what measures might enable the access to housing.
\end{abstract}

Keywords: Housing, Access to housing, pandemic, prices and mortgage.

Sumario: I. Introducción. II. Efectos Económicos De la Pandemia. 2.1. Efectos De La Pandemia Sobre EL Crecimiento Económico. 2.2. Efectos Macroeconómicos de La Pandemia En El Sector De La Construcción. III. Efectos De La Pandemia Sobre El Mercado De La Vivienda. 3.1. Vertiente De La Demanda. 3.2. Vertiente De La Oferta. 3.3. Precios. 3.4. Otros Indicadores Del Mercado De La ViVIENDa. IV. Dónde Estamos y Adónde VAMOS. V. BIBLIOGRAFÍA.

\section{INTRODUCCIÓN}

El objetivo de la presente investigación es mostrar como se ha visto afectado el acceso a la vivienda por el Covid-19 y por una posible nueva ley de vivienda. La tesis defendida es que el estallido de la pandemia del coronavirus está dificultando el ya nada sencillo ac- 
ceso a la vivienda de ciertos colectivos sociales. Y es que, como vemos a continuación, el efecto del covid-19 en la economía en general, y en el empleo en particular, no está siendo compensado suficientemente por una contención del precio de la vivienda.

Para ello el trabajo se ha estructurado en tres apartados. En el primero, se analizan muy sucintamente los efectos de la pandemia sobre la economía, estudiando en primer lugar su influencia en el crecimiento económico y, en segundo lugar, se menciona algún aspecto relevante de la crisis sanitaria en el sector de la construcción.

En un segundo apartado se examinan los efectos de la pandemia en el mercado inmobiliario, más concretamente se analizan las principales consecuencias del coronavirus sobre la vertiente de la demanda y de la oferta de este mercado, sobre la evolución de los precios del bien objeto de estudio (la vivienda), y sobre otros elementos del mercado inmobiliario (como los cambios en las preferencias de los demandantes, tiempo de venta, esfuerzo de acceso a la vivienda, etc.).

En un tercer y último apartado se elaboran unas previsiones a cerca de la evolución de este mercado, se señalan los factores que en ella influirán, y se termina destacando medidas de política económica que contribuyan a la recuperación del sector.

\section{EFECTOS ECONÓMICOS DE LA PANDEMIA}

\subsection{Efectos de la pandemia sobre el crecimiento económico.}

En este primer apartado se procede a estudiar los efectos de la crisis sanitaria generada por el Covid-19 sobre la economía, en general, y sobre el sector de la construcción, en particular.

Principales efectos económicos del Covid-19 a nivel geográfico:

- Caída muy acusada del producto interior bruto (PIB) mundial:

○ más acusada que en la crisis de 2008 (2009: -1,67\%; 2020: -2,6\%),

$\circ$ pero transitoria (sujeta a elevada incertidumbre).

- Fuerte contracción de la actividad económica en la Zona Euro:

- más intensa en el arco mediterráneo,

- pero se espera recuperación (aunque sujeta a incertidumbre).

- La actividad económica nacional experimento una fuerte caída:

- incidencia especialmente acusada en el mercado laboral,

- con fuerte impacto inicial y recuperación intensa. 


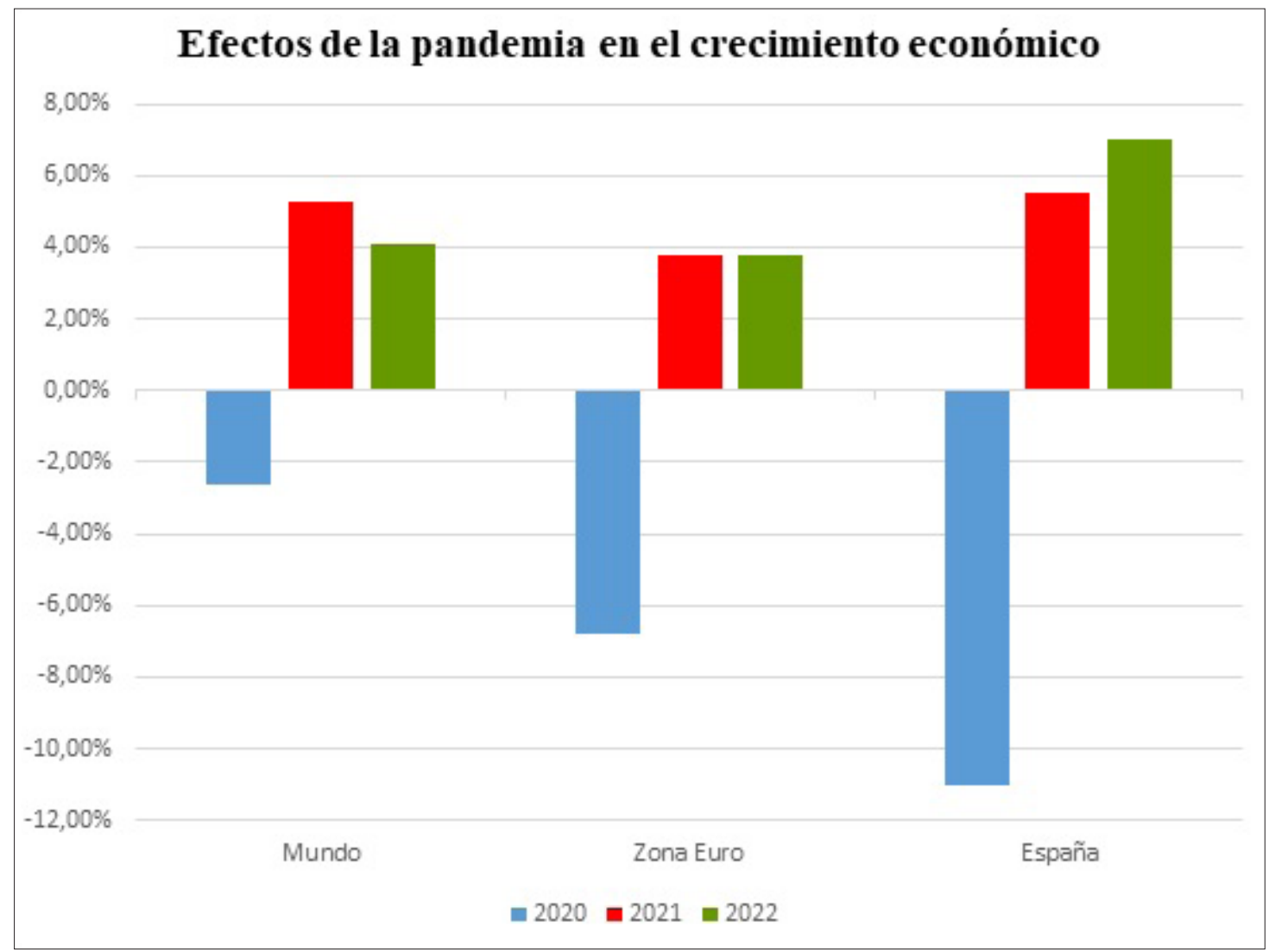

Fuente: elaboración propia a partir de BBVA Research (2021b)

La actividad económica mundial cayó un 2,6\% en el ejercicio pasado como consecuencia del Covid-19. En el corto plazo el crecimiento seguirá estando afectado por la evolución de la pandemia, pero el respaldo de las políticas económicas expansivas y los programas de vacunación contra el coronavirus impulsarán el crecimiento a partir de mediados del presente año. Por ello, se espera que el PIB mundial se incremente más de un 5\% en 2021 y un $4 \%$ en 2022 .

La Comisión Europea, que el pasado 10 de febrero presentó sus Previsiones de Invierno, estimó una caída del $\mathbf{6 , 4 \%}$ en el PIB de la UE y del 6,8\% en la Zona Euro. Por lo que la economía europea, dada su estructura, se ha visto más afectada que la media mundial. En el seno de la Unión destaca el peor comportamiento de los países del arco Mediterráneo, con un especial protagonismo para España ${ }^{1}$. En el caso de las economías europeas, además del mayor impacto negativo inicial de la pandemia, destaca también que la recuperación será más lenta, pues se espera un crecimiento de la actividad económica para los dos próximos ejercicios en el entorno del $\mathbf{3 , 8 \%}$.

De acuerdo con datos publicados por distintos organismos internacionales, la española ha sido, junto con la argentina, la economía de los países occidentales que más

1 Según este informe, España se contrajo un $11 \%$, Grecia un $10 \%$, Italia un $8,8 \%$ y Francia un $8,3 \%$. Véase COMISIÓN EUROPEA, "Previsiones económicas de invierno 2021", disponible en https://ec.europa.eu/info/ sites/info/files/economy-finance/ip144_en_1.pdf, 2021. 
negativamente se ha visto afectada por la crisis del Covid-192. Ello, entre otros motivos, por el mayor peso en nuestra economía de sectores más relacionados con la movilidad y el contacto. Según datos del Instituto Nacional de Estadística (INE), la economía española se contrajo un $11 \%$ en 2020 . No obstante, se espera un importante repunte de la actividad económica nacional para los dos próximos ejercicios (un crecimiento del 5,5\% en 2021 y de un $7 \%$ en 2022) y ello motivado por una vacunación masiva, una política fiscal expansiva recogida en los presupuestos generales del Estado para 2021, la llegada de los fondos europeos Next Generation (paquete de recuperación de la Covid-19), unas medidas monetarias adoptadas por el Banco Central Europeo (BCE) muy acomodaticias y una elevada capacidad productiva sin utilizar. $^{3}$

Sin embargo, no es menos cierto que todavía existen riesgos a corto plazo que es preciso neutralizar: mayor control en las sucesivas olas de la enfermedad y de las distintas cepas, acelerar la velocidad de la vacunación, utilización eficiente de los fondos europeos, y alcanzar grandes consensos sobre reformas que incrementen la productividad de nuestra economía ${ }^{4}$.

\subsection{Principales efectos macroeconómicos de la pandemia en el sector de la construcción 5}

El sector de la vivienda se desaceleró en 2019 en un entorno de ralentización de los principales agregados económicos. A principios de 2020, en línea con la evolución económica en general, el sector se mostró vigoroso, con una disminución de la demanda y una escasez de la oferta que generarían incrementos de los precios y dificultades crecientes para el acceso a la vivienda. Pero ese panorama cambió con la aparición del Covid-19 y los efectos que consigo trajo la pandemia: desde el confinamiento al cierre de actividades económicas.

En este contexto el mercado de la vivienda experimentó una brusca caída, pero obviamente esta crisis no ha sido igual a la del 2008. Esta última se caracterizó por una burbuja de precios, crisis de solvencia del sistema financiero, y un gran peso del sector de la construcción con elevado nivel de endeudamiento en el conjunto de la economía nacional. La crisis actual tiene su origen en un factor externo (la pandemia), el sector está mucho menos endeudado y no ha contribuido a incrementar el stock de vivienda nueva.

2 Véase ORGANIZACIÓN PARA LA COOPERACIÓN Y EL DESARROLLO ECONÓMICOS (OCDE), "Perspectivas económicas. Diciembre 2020", disponible en https://www.oecd.org/perspectivas-economicas/, 2020.

3 Con relación a la previsible evolución económica española véase BANCO DE ESPAÑA, "Informe trimestral de la economía española", Boletín Económico, 4/2020, 2021; BBVA RESEARCH, "Situación España Primer Trimestre 2021", disponible en https:/www.bbvaresearch.com/publicaciones/situacion-espana-primer-trimestre-2021/, 2021; FELGUEROSO, F. ET ALIA, “Aspectos económicos de la crisis del Covid-19”, Estudios sobre la Economía Española de Fedea, no 9, 2021; y TORRES, R. y FERNÁNDEZ, M.J., "Los rebrotes de la pandemia empeoran las expectativas económicas”, Cuadernos de Información Económica, nº 278, págs.: 1-10, 2020.

4 Para un estudio más amplio de los efectos del Covid-19 en la política económica española véase TORRES, R. y FERNÁNDEZ, M.J., "La política económica española y el Covid-19", Cuadernos de Información Económica, n 275, págs.: $1-7,2020$.

5 A lo largo de este trabajo en muchas ocasiones parece usarse indistintamente la expresión sector de la construcción y sector inmobiliario, pero no se trata de sinónimos, ya que el sector inmobiliario agrupa al sector de la construcción (Código F de la Clasificación Nacional de Actividades Económicas, CNAE-2009) y aquellas actividades de intermediación inmobiliaria (Código L de la Clasificación Nacional de Actividades Económicas, CNAE-2009). 
La crisis económica generada por la pandemia está afectando al mercado inmobiliario, pero en menor medida que en la crisis de 2008. Además, a diferencia de lo acontecido en 2008, no se prevé un crack del sector de la vivienda, ya que la demanda se mantiene merced a unos tipos de interés (e hipotecarios) muy bajos, la atracción del sector nacional para inversores internacionales, y la ausencia de inversiones alternativas más rentables.

La pandemia ha acelerado el fin del ciclo inmobiliario, pero la mayoría de los autores ya predecían este final sin necesidad de ninguna aportación exógena como ha sido el Covid-19. ${ }^{6}$

En términos del PIB, el sector de la construcción no ha sido el más afectado por la crisis sanitaria y, además, no ha hecho más que intensificar la desaceleración ya existente. En el gráfico adjunto se observa como, en el segundo trimestre de 2020 (el más afectado por la primera ola de la pandemia), la rama de la industria manufacturera $(-22,44 \%)$, la rama de comercio, transporte y hostelería (-40\%), y la rama de actividades artísticas, recreativas y otros servicios $(-32,2 \%)$, presentan mayores tasas de crecimiento negativo trimestral que el sector de la construcción $(21,9 \%)^{7}$. Por lo que se puede afirmar sin miedo a equivocarse que en la crisis económica generada por el Covid-19, a diferencia de lo ocurrido en la crisis de 2008, el sector de la construcción no ha sido el peor parado.

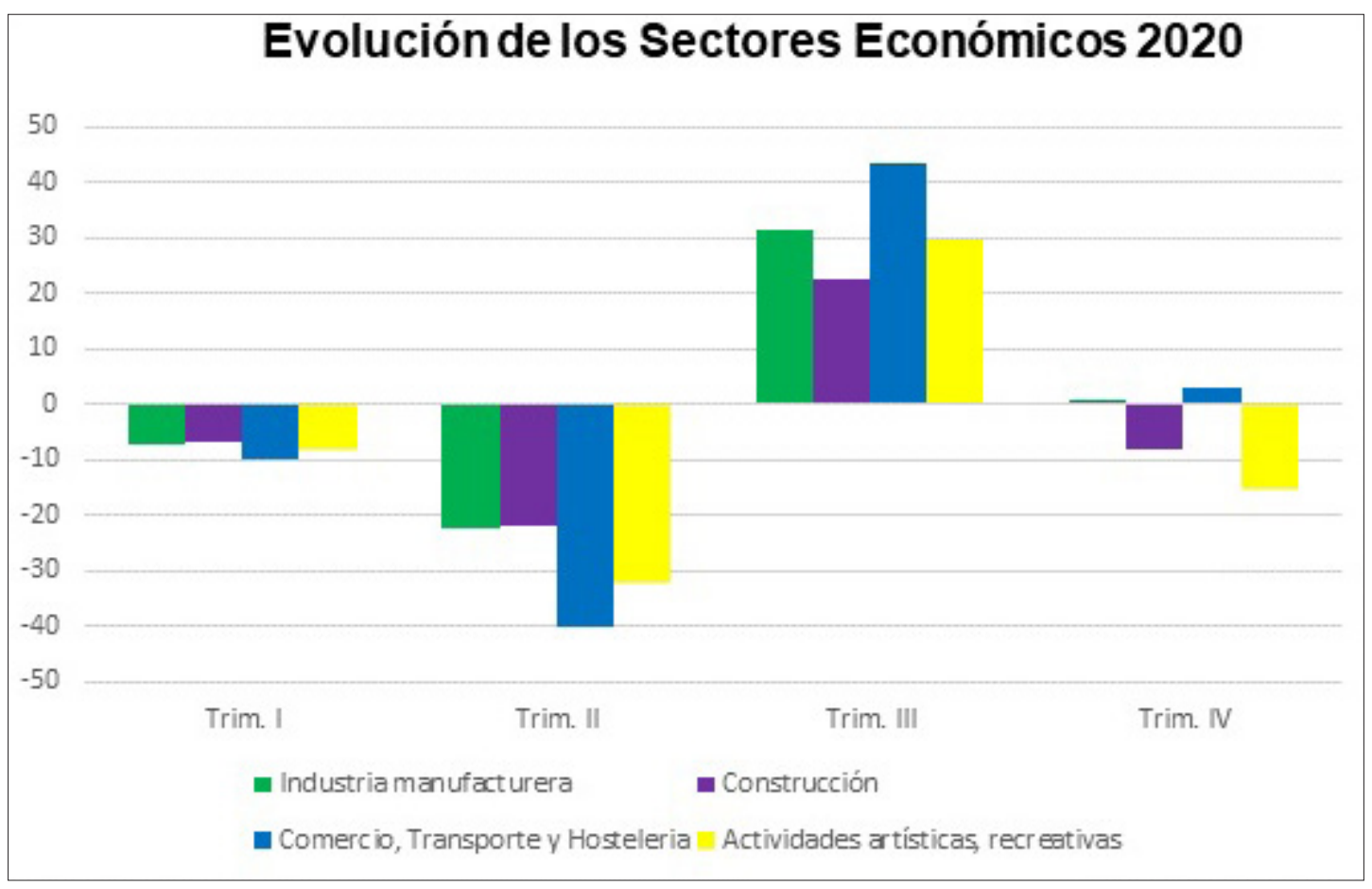

Fuente: elaboración propia a partir de INE (2021a)

6 Esta opinión es defendida, entre otros, en BBVA RESEARCH, "Situación inmobiliaria. Diciembre 2020", disponible en file://C:/Users/c146a/Downloads/Situacion_Inmobiliaria_dic20.pdf, 2021; OCAÑA, C. y TORRES, R., "Impacto de la pandemia sobre el sector inmobiliario", Cuadernos de Información Económica, no 278, págs.: 11-16, 2020; RAYA, J.M., "El impacto de la pandemia en el mercado de la vivienda en España: diagnóstico y políticas", disponible en https://dobetter.esade.edu/es/vivienda-coronavirus, 2020; etc.

7 Véase INE, "Contabilidad Nacional Trimestral de España: principales agregados. Cuarto trimestre de 2020. Avance", disponible en https://www.ine.es/daco/daco42/daco4214/cntr0420a.pdf, 2021. 
De acuerdo con los datos proporcionados por el INE en la contabilidad nacional trimestral, se aprecia también como en los últimos trimestres de 2019 el sector de la construcción presentaba ya valores negativos $(-0,3 \%$ y $-0,1 \%$ en el tercer y cuarto trimestre de 2019 , respectivamente). A la luz de estos datos se esperaba una tasa de crecimiento negativa para 2020, pero esta tendencia decreciente se aceleró considerablemente por los efectos de la crisis sanitaria, registrándose significativas caídas trimestrales en el sector durante tres de los cuatro trimestres de $2020:-6,9 \% ;-21,9 \% ;+22,5 \%$ y $-8,1 \%$, sucesivamente.

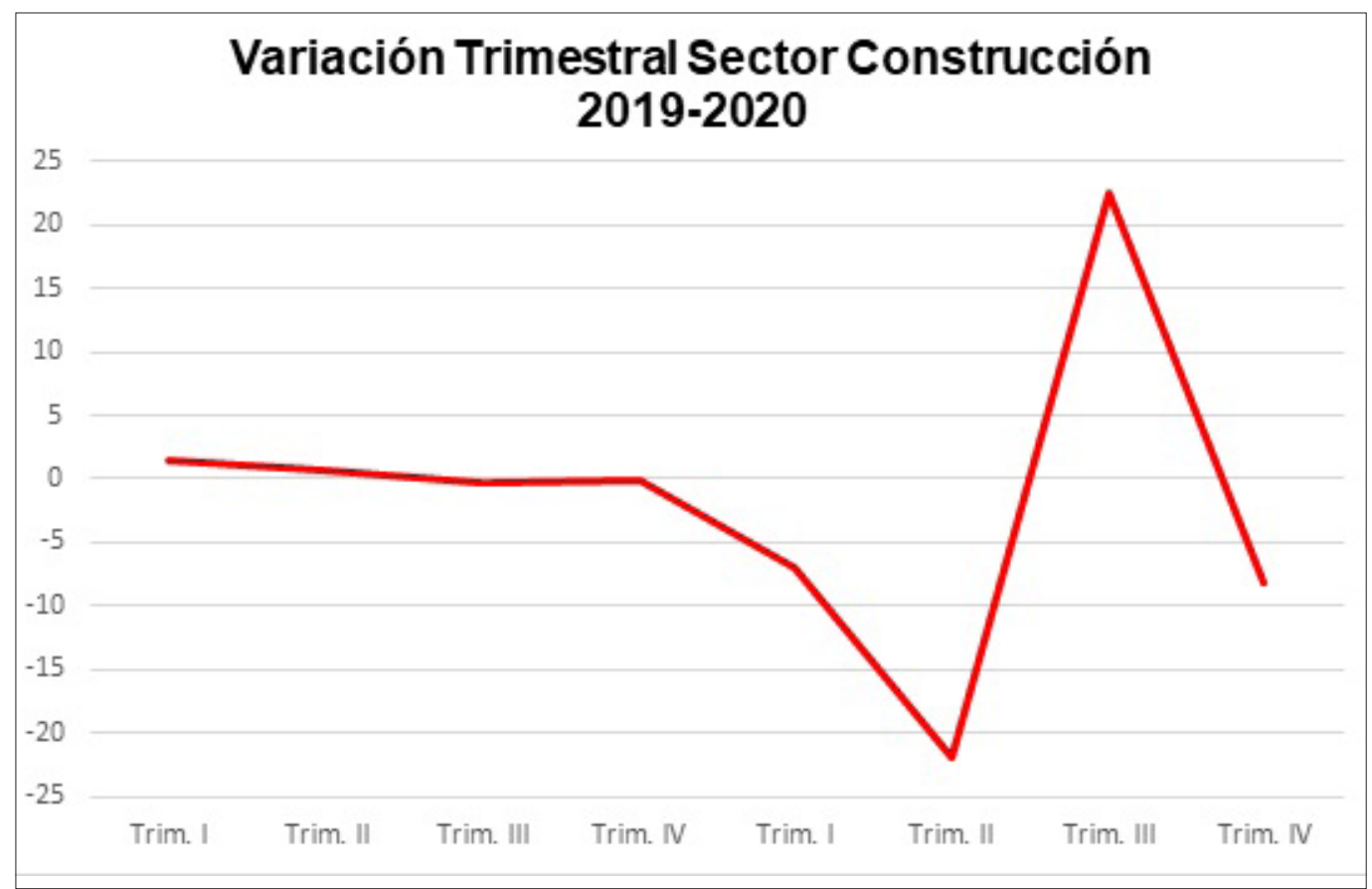

Fuente: elaboración propia a partir de INE (2021a)

Es bien sabido que el sector de la construcción es uno de los más intensivos en mano de obra, fundamentalmente no cualificada, por lo que esos efectos negativos de la pandemia en el producto interior bruto del sector de la construcción han tenido su reflejo en términos de empleo. Así, durante el ejercicio 2020 la cuantía de horas trabajadas en el sector de la construcción sufrió importantes reducciones ${ }^{8}$ pero, debido a los expedientes de regulación temporal de empleos (ERTEs), el número de ocupados en este sector económico apenas se redujo con relación al anterior ejercicio económico, pues si bien el número total de ocupados en España disminuyó en 622.000 personas, de ellos solo 3.700 lo fueron en el sector de la construcción. En el mismo sentido, si el número de desempleados en la economía española en el pasado ejercicio aumentó en 527.900 personas, el sector de la construcción tan solo aportó 7.900. ${ }^{9}$

8 De acuerdo con los datos del INE, el número de horas trabajadas en el sector de la construcción se han reducido interanualmente el $-7.3 \%,-31.1 \%,-2,8 \%$ y el $-5,3 \%$, durante los cuatro trimestres de 2019 . Véase INE, "Contabilidad Nacional Trimestral de España: principales agregados. Cuarto trimestre de 2020. Avance”, disponible en https:// www.ine.es/daco/daco42/daco4214/cntr0420a.pdf, 2021.

9 Para un análisis más detallado de los efectos de la pandemia en el mercado laboral véase INE, "Encuesta de Población Activa. (EPA). Cuarto trimestre de 2020", disponible en https://www.ine.es/daco/daco42/daco4211/epa0420.pdf, 2021. 


\section{EFECTOS DE LA PANDEMIA SOBRE EL MERCADO DE LA VIVIENDA}

\subsection{Vertiente de la demanda}

Se ha de tener en cuenta que después de cuatro ejercicios con crecimiento en el número de transacciones de viviendas, en 2019 las compraventas se redujeron un 3\%, y ello a pesar de superar las 500 mil transacciones. Por su parte, en el ejercicio 2020 la compraventa de viviendas experimentó una caída de casi el 20\% como consecuencia de la primera ola de la pandemia ${ }^{10}$. Por lo tanto, la llegada de la pandemia no hizo más que intensificar la tendencia decreciente ya iniciada en el ejercicio anterior.

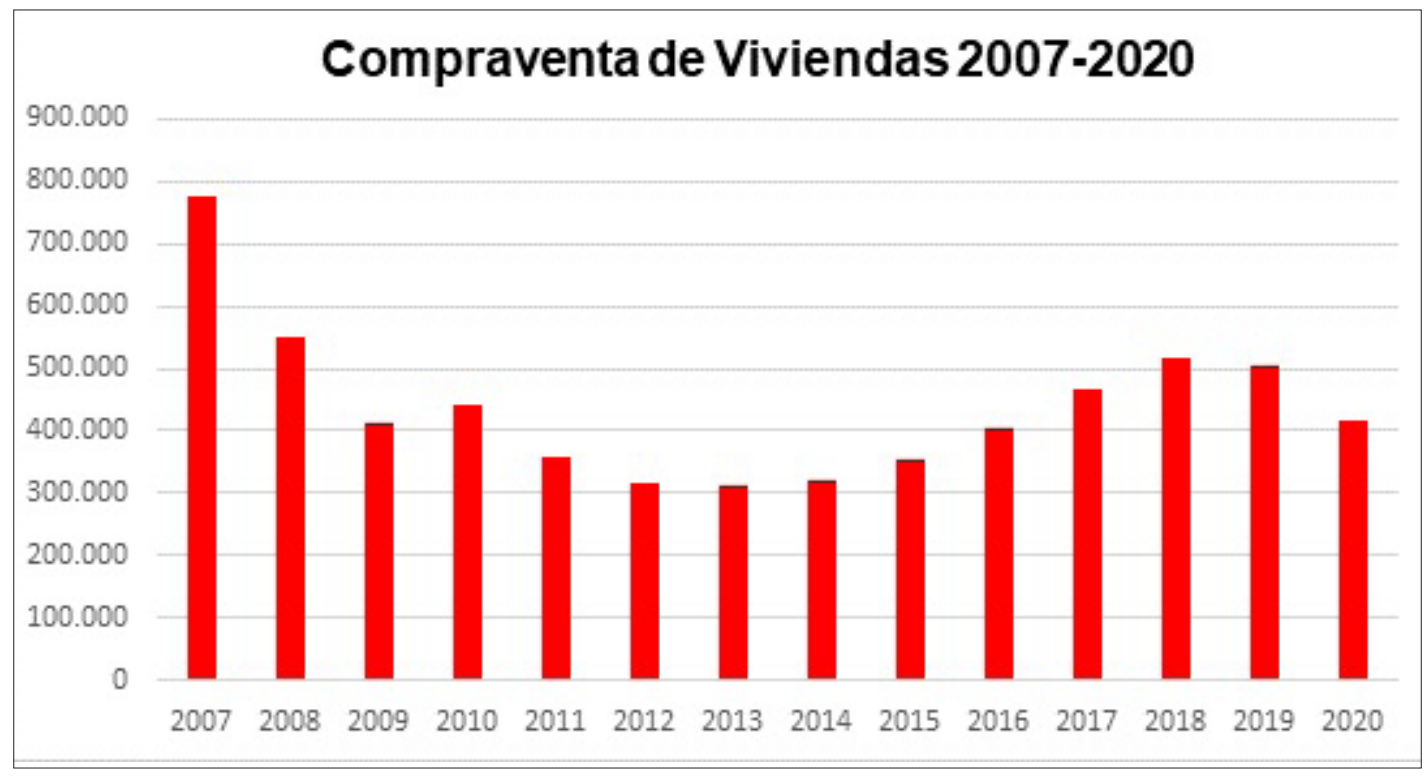

Fuente: elaboración propia a partir de INE (2021c)

El coronavirus inicialmente supuso una significativa reducción, que fue parcialmente recuperada tras la finalización del confinamiento ${ }^{11}$, más concretamente:

- Los primeros meses de 2020 presentaron una cierta estabilización en el número de compraventas.

- Una importante reducción interanual a partir del mes de marzo hasta agosto. Durante los meses del confinamiento las ventas de viviendas cayeron un 39\%, un $54 \%$ y un $34 \%$ (abril, mayo y junio, respectivamente). Como ya hemos señalado, las ventas ya descendieron en los últimos meses de 2109 y enero

10 Véase INE, "Estadística de transmisiones de derechos de la propiedad. Diciembre 2020 y año 2020", disponible en https://www.ine.es/daco/daco42/etdp/etdp1220.pdf, 2021.

11 De acuerdo con un trabajo del profesor Raya, casi el $90 \%$ del total de viviendas puestas a la venta durante el primer semestre de 2020 lo fueron antes de la declaración del estado de alarma (14 de marzo de 2020). Véase RAYA, J.M., "El impacto de la pandemia en el mercado de la vivienda en España: diagnóstico y políticas", disponible en https:// dobetter.esade.edu/es/vivienda-coronavirus, pp. 7, 2020. 
de 2020, pero esta tendencia se aceleró por la crisis económica asociada al Covid-19.

- Las positivas expectativas generadas por el proceso de vacunación parecen haber insuflado aire fresco al sector inmobiliario en el tramo final de 2020, observándose una cierta recuperación en los últimos meses del ejercicio; así, de acuerdo con los últimos datos del INE correspondientes a la compraventa de viviendas, noviembre fue el primer mes con aumento en el número de viviendas vendidas desde el comienzo de la pandemia.

No obstante, ese leve incremento del mes de noviembre no impidió que el ejercicio 2020 se cerrase con una caída en el intercambio inmobiliario entorno al $20 \%$.

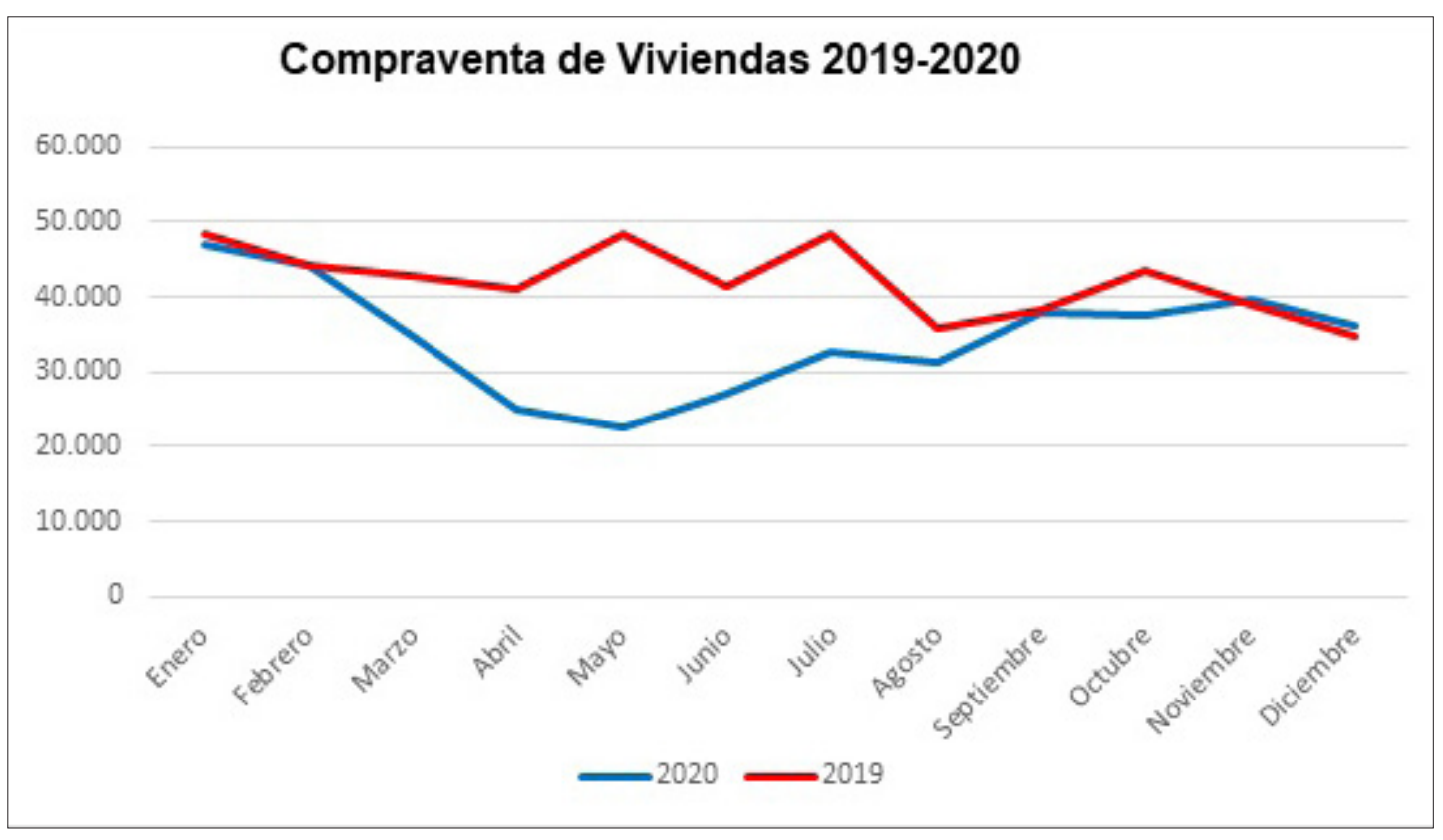

Fuente: elaboración propia a partir de INE (2021c)

Otro hecho a destacar es que, más que en las compraventas de vivienda nueva, las reducciones más importantes se produjeron en las de vivienda de segunda mano y en las compras realizadas por extranjeros. ${ }^{12}$

Durante los meses del confinamiento, especialmente significativa fue la caída de la compra de viviendas por parte de foráneos, con una reducción cercana al 50\% (pasando de unas ventas de unas 15 mil viviendas en el primer trimestre de 2020 a unas 8 mil en el segundo trimestre). A esta importante disminución ha contribuido también la salida del Reino Unido de la Unión Europea (el Brexit), pues ha de tenerse en cuenta que los británicos han sido tradicionalmente los extranjeros que más vivienda compran en nuestro país y, obviamente, el Brexit está ocasionando una menor compra de inmuebles en el territorio de sus ex

12 Véase COLEGIO DE REGISTRADORES DE LA PROPIEDAD, BIENES MUEBLES Y MERCANTILES DE ESPAÑA, "Estadística registral inmobiliaria, $4^{\circ}$ trimestre 2020", disponible en hhttps://www.registradores.org/ documents/33383/321222/ERI_4T_2020.pdf/ab20528b-8b4f-8b25-6ad6-2ff969a41568?t=1613131363018, 2021. 
socios comunitarios. No obstante, en los últimos trimestres de 2020, y acorde con la evolución general de las compras, las adquisiciones inmobiliarias de extranjeros aumentaron.

Un segundo elemento que se estudia en la vertiente de la demanda es la evolución del crédito hipotecario ${ }^{13}$. La primera idea a destacar con relación a esta variable es que, si bien se ha producido a su vez una reducción de las hipotecas, esta ha sido menor que las transacciones (compraventas).

Las hipotecas constituidas sobre las viviendas cayeron en 2020 con relación al ejercicio previo más de un 7\% (un 7,6\%), cuantía muy inferior a la registrada en las compraventas (un 17,7\%). Una posible explicación a esta mayor fortaleza de las hipotecas es que disminuyeron en mayor medida las compras de aquellos agentes que no necesitaban hipotecas (los inversores) que las de las economías domésticas que compraban la vivienda para su uso personal.

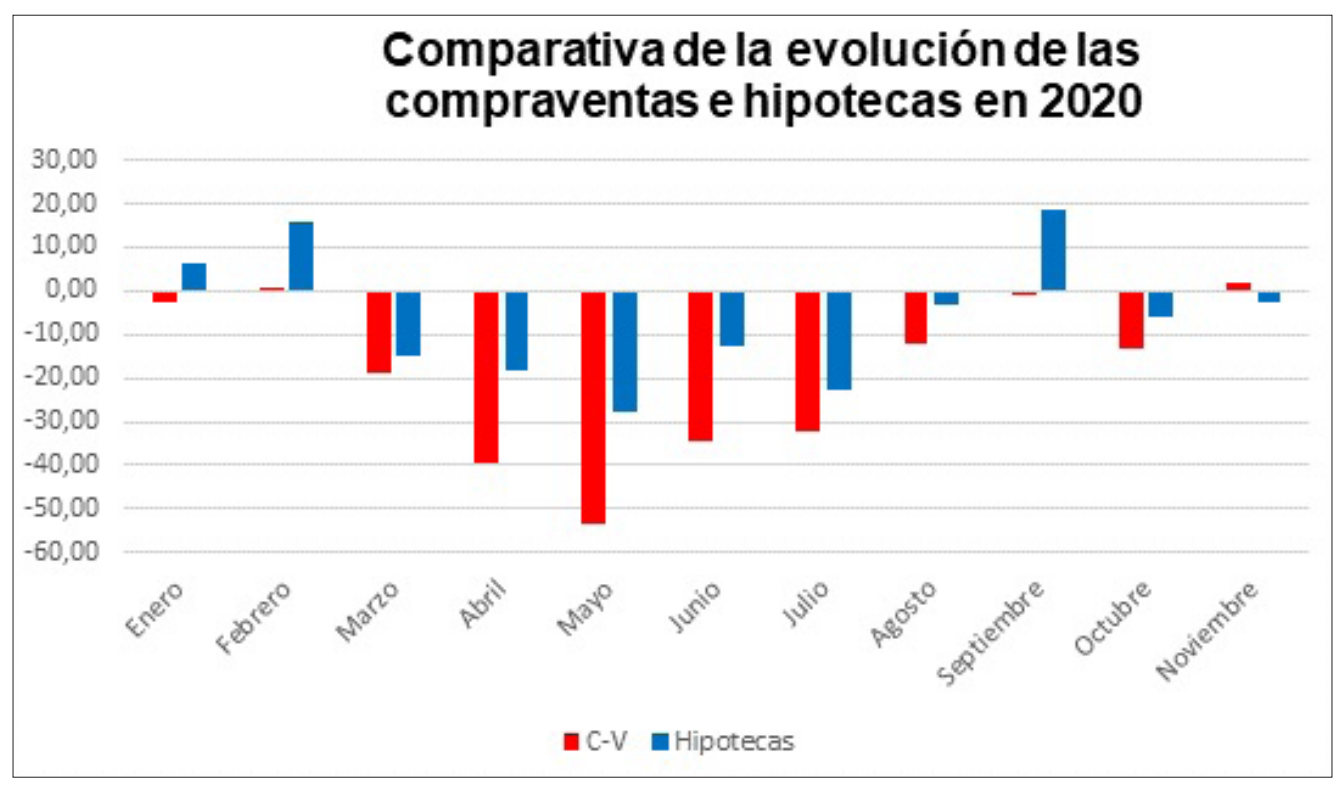

Fuente: elaboración propia a partir de INE (2021c) e INE (2021d)

Esta evolución tan dispar entre el número de compraventas $(\mathrm{C}-\mathrm{V})$ y el de hipotecas contratadas, no vista hasta entonces en igual medida, puede ser achacable también a la dilación en el trabajo de notarías y registros causada por la pandemia.

El tipo de interés aplicado a las hipotecas de viviendas sigue siendo bastante reducido (en el entorno del 2\%).

Con relación a la vivienda demandada, el coronavirus ha provocado un cambio en las preferencias de los compradores: se prima el tamaño y la existencia de elementos exteriores frente al criterio tradicional de la ubicación. Tras la experiencia del confinamiento, los compradores de viviendas han reaccionado optando por viviendas más grandes y, a poder ser, con espacios abiertos. Así, se observa una creciente demanda de chalets y vi-

13 Véase INE, "Estadística de Hipotecas. Diciembre 2020 y año 2020", disponible en https://www.ine.es/daco/ daco42/daco426/h1220.pdf, 2021, y MINISTERIO DE TRANSPORTES, MOVILIDAD Y AGENDA URBANA, "Observatorio de vivienda y suelo. Tercer trimestre 2020", disponible en https://apps.fomento.gob.es/CVP/ handlers/pdfhandler.ashx?idpub=BAW079, 2020. 
viendas unifamiliares, del interior de las ciudades a zonas periféricas y municipios con baja densidad de población.

Con el confinamiento muchos ciudadanos trasladaron sus oficinas, gimnasios, cocinas y centros de ocio a sus hogares. Ello supuso un cambio en la concepción de la vivienda: se pasó de considerarlas como un lugar para dormir y descansar a un lugar para vivir, o mejor aún: de un espacio para vivir en él a un espacio para ser vivido. El recibidor se transformó en un recinto de desintoxicación y saneamiento, el salón se adaptó para convertirse también en nuestra oficina, el dormitorio amplió sus funciones para servir de espacio para realizar otro tipo de actividades físicas (gimnasio deportivas), todos los componentes de la cocina fueron más utilizados y se les dotó de mayor equipamiento, los compradores se decantaron por casas con elementos exteriores como balcones, terrazas, jardines, etc. Como dirían algunos de nuestros políticos, nuestros hogares se adaptaron a la nueva normalidad.

Antes de finalizar con el análisis de la vertiente de la demanda me gustaría destacar tres ideas que considero esenciales en esta sección:

- El mal comportamiento del mercado laboral durante la primera ola de la pandemia (aumento del desempleo, reducción de la renta de los trabajadores inmersos en ERTEs, desaparición de trabajadores autónomos, etc.) propició una drástica reducción de la demanda inmobiliaria, motivada por la disminución de la renta disponible de las familias.

- Las compraventas de viviendas experimentaron una significativa reducción durante los primeros meses de la pandemia (hasta el mes de mayo se estima una caída del 40\%). En los primeros meses de la desescalada se observó una ligera recuperación, o al menos estabilización.

- A pesar de lo anterior, España continúa siendo un país con un hondo sentimiento de propiedad: a día de hoy los hogares españoles que tienen en propiedad la vivienda están cerca del $80 \%$ (exactamente $76 \%$, siete puntos por encima de la media de la Unión Europea) ${ }^{14}$.

\subsection{Vertiente de la oferta}

Con relación a la vertiente de la oferta del mercado inmobiliario, señalar en primer lugar como el número de viviendas construidas pasó de una 600 mil en 2006 a menos de 100 mil en 2019, y ello a pesar de que en los últimos años (2016-2019) se produjo una ligera recu-

14 Según el INE, el porcentaje de hogares con vivienda en régimen de propiedad se ha reducido en los últimos 15 años unos cinco puntos porcentuales a favor del régimen de alquiler, motivado por una mayor movilidad laboral, por incrementos salariales inferiores al de los precios de vivienda, elevada tasa de paro juvenil, boom de alquileres turísticos, etc. De acuerdo con esta misma fuente, en la actualidad el número de hogares en España se sitúa en unos 19 millones. Véase INE, “Encuesta de Condiciones de Vida (ECV). Año 2019”, disponible en https://www.ine.es/ prensa/ecv_2019.pdf, 2020. 
peración ${ }^{15}$. Este número de viviendas nuevas fue inferior al de creación de hogares (120 mil según el INE), lo que motivo una escasez del bien y una presión al alza de los precios.

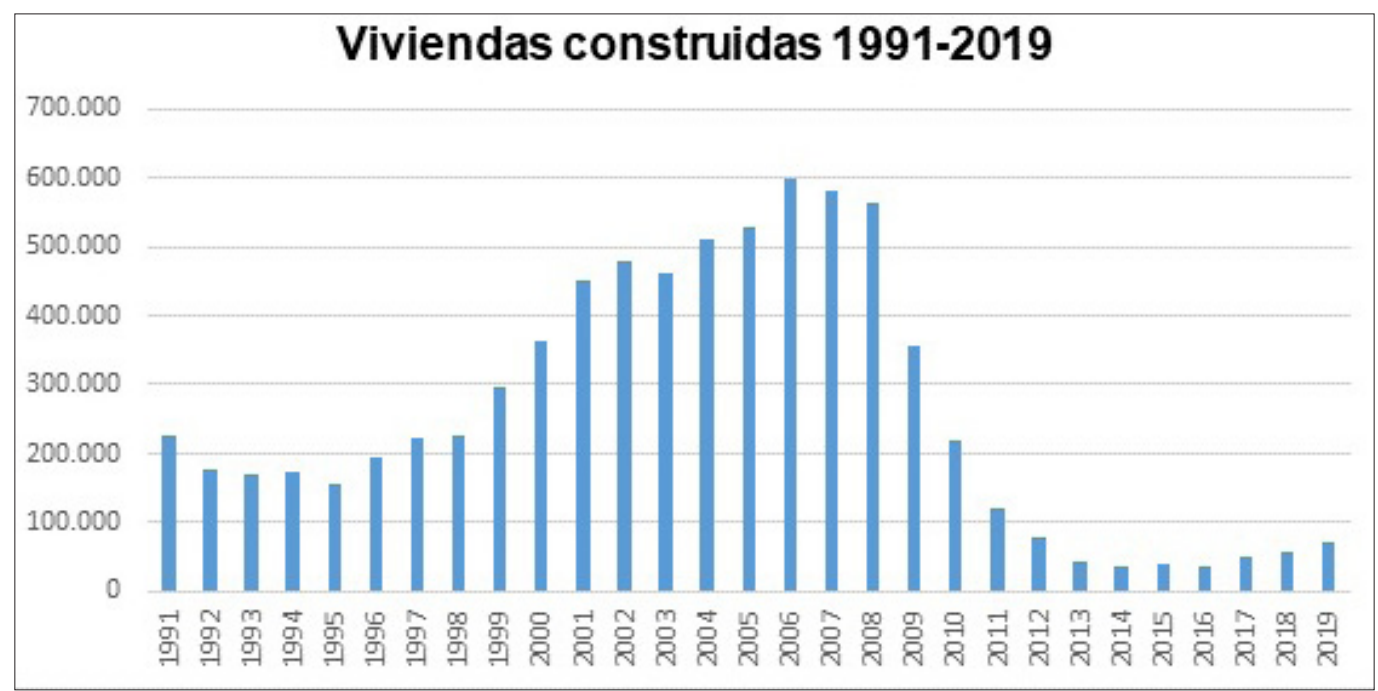

Fuente: elaboración propia a partir de Ministerio de Transportes, Movilidad y Agenda Urbana (2021a)

La construcción de vivienda nueva prácticamente se paralizó en los primeros meses de 2020 debido a los efectos del Covid-19 y a los consiguientes estados de alarma. No obstante, con posterioridad, a partir del mes de mayo, los datos nos muestran una robusta recuperación. Así, resulta significativa la recuperación del empleo en el sector de la construcción, la evolución de los visados de obra nueva, del consumo de cemento, etc. Todos estos indicadores señalan una mejora en la oferta de la vivienda tras el primer cuatrimestre de 2020.

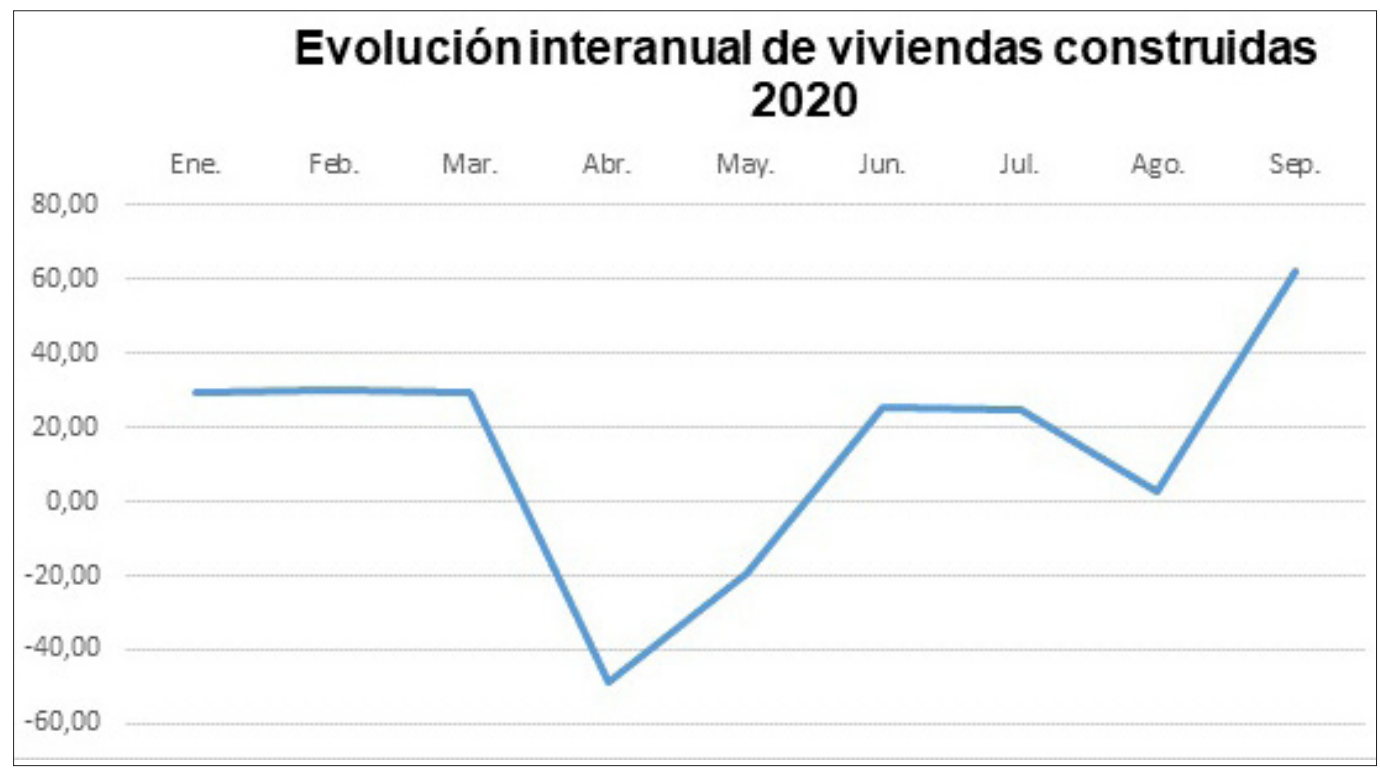

Fuente: elaboración propia a partir de Ministerio de Transportes, Movilidad y Agenda Urbana (2021a)

15 Véase MINISTERIO DE TRANSPORTES, MOVILIDAD Y AGENDA URBANA, "Número de viviendas libres terminadas", disponible en https://apps.fomento.gob.es/BoletinOnline2/?nivel=2\&orden=32000000, 2021. 
En relación al consumo del cemento, se observa una drástica caída en los primeros meses del confinamiento, con una reducción de casi el 50\% en el mes de abril, y en los meses posteriores se alcanzó un consumo similar al de los anteriores a la crisis sanitaria. ${ }^{16}$

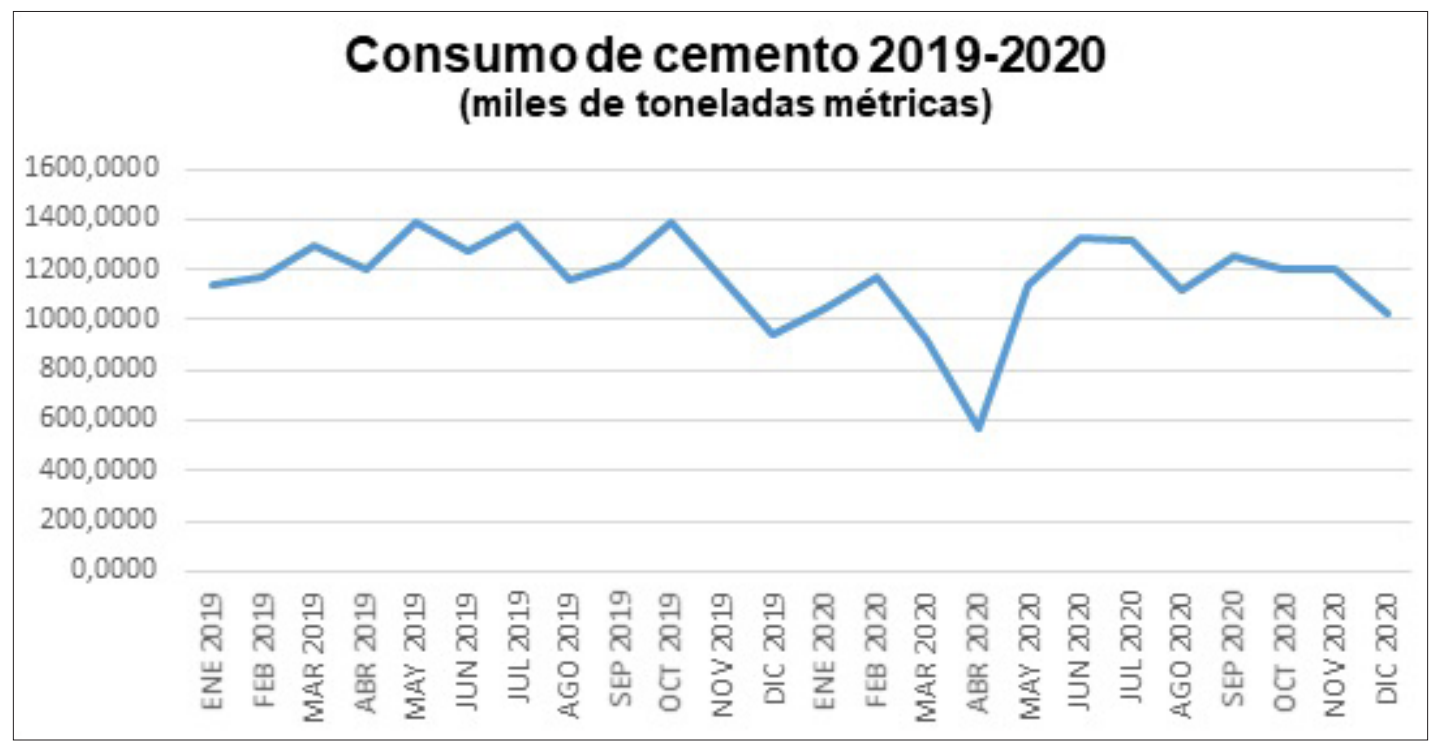

Fuente: elaboración propia a partir de Banco de España (2021b)

Por su parte, los visados de obra nueva (auténtico indicador adelantado del sector de la construcción) se contrajeron en los 11 primeros meses del año 2020 un 13\%, con importantes caídas en abril y mayo y una cierta recuperación en los últimos meses analizados. ${ }^{17}$

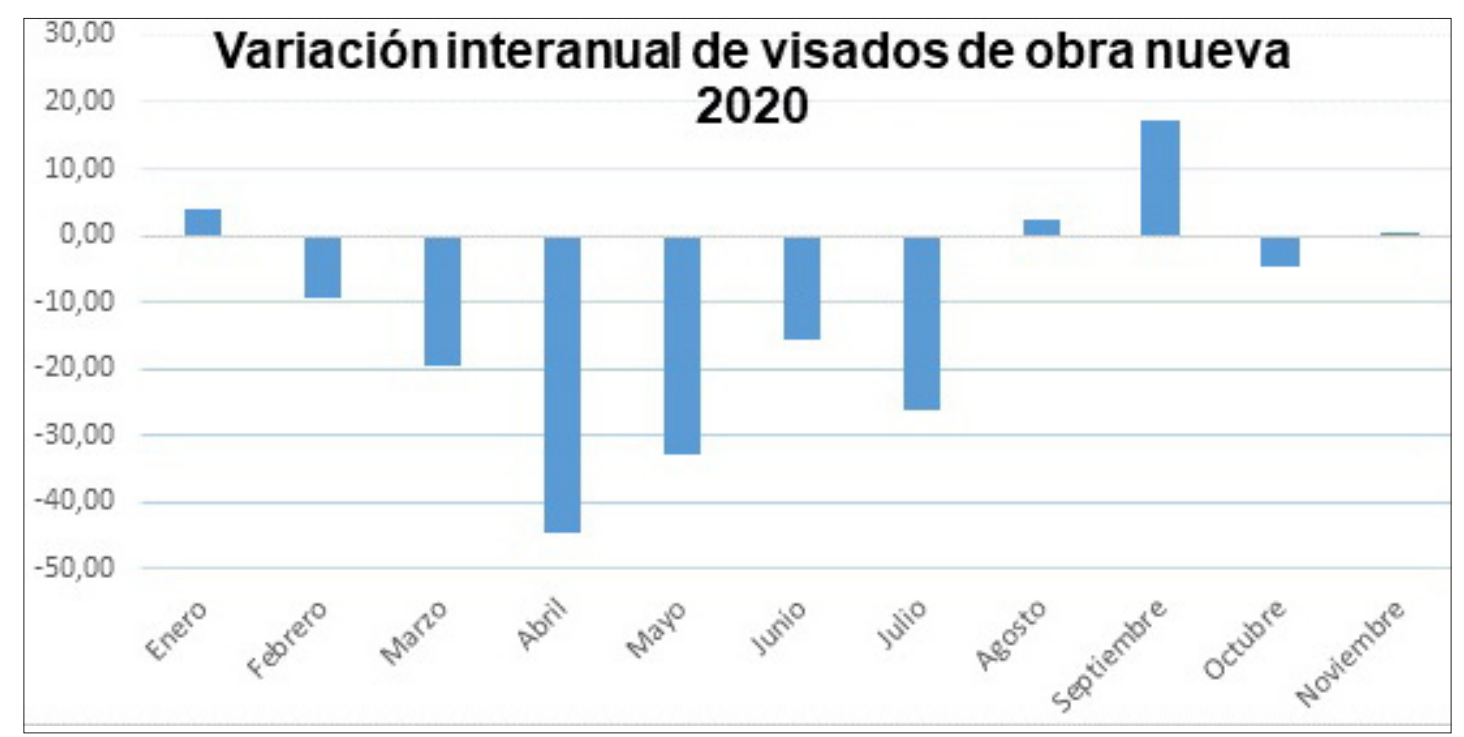

Fuente: elaboración propia a partir de Ministerio de Transportes, Movilidad y Agenda Urbana (2021b)

16 Véase esta información en el BANCO DE ESPAÑA, "Estadísticas. Indicadores de construcción, acero y cemento", disponible en https://www.bde.es/webbde/es/estadis/infoest/bolest23.html, 2021.

17 Véanse los datos recogidos en MINISTERIO DE TRANSPORTES, MOVILIDAD Y AGENDA URBANA, "Estadística de Visados de Dirección de Obra (Estadísticas de Obras en Edificación)", disponible en https://www. fomento.gob.es/BE/?nivel=2\&orden=09000000, 2021. 
Estos dos indicadores de oferta parecen mostrar una reducción significativa en la actividad constructora, pero reducción transitoria, por lo que el efecto final sobre el total del año no ha sido tan abrupto como podría haber sido de no ser por ese carácter transitorio.

Al analizar la vertiente de la oferta en el pasado ejercicio, otro hecho a tener en cuenta es que los deseos de venta de las familias españolas aumentaron con la crisis sanitaria debido a las necesidades de liquidez de muchas de ellas y al incremento de inmuebles heredados.

De igual manera, en los últimos años, también se produjo un aumento en la oferta de vivienda de alquiler, aunque no suficiente para cubrir la demanda, en este caso motivada por una más que interesante rentabilidad.

\subsection{Precios $^{18}$}

Al analizar la evolución de los precios en el sector de la vivienda y como estos se han vistos afectados por la pandemia, destacar como cuestión previa que el precio de la vivienda tiene una importante influencia en las decisiones de consumo de las familias, ya que la vivienda familiar es el activo inmobiliario que supone más de un $70 \%$ de la riqueza de las familias españolas.

Después de su dura caída tras la crisis económica de 2008, el precio de la vivienda aumentó desde 2014, pero en los tres últimos ejercicios se ha observado una moderación en este incremento. Tendencia que se aceleró con el Covid-19. A la luz de los datos publicados por distintos organismos e institutos estadísticos parece evidente que, si bien la pandemia ha acelerado la contención de los precios, es esta una tendencia ya iniciada en ejercicios anteriores. El covid-19 no ha iniciado un proceso de desaceleración en el ritmo de crecimiento de los precios, si no que ha acelerado la tendencia decreciente existente de ejercicios previos. En este sentido, señalar que distintos estudios preveían una contención e incluso reducción de los precios a finales de $2020 \mathrm{sin}$ considerar la pandemia en sus análisis ${ }^{19}$.

18 En esta sección trabajamos con datos elaborados por el INE, organismo que elabora sus estadísticas a partir de datos de tasaciones proporcionados por el Ministerio de Transportes, Movilidad y Agenda Urbana, y estos datos suelen tener un pequeño retraso con relación a aquellas otras estadísticas de precios que se elaboran a partir de compraventas. Véase INE, “Índice de Precios de Vivienda. Tercer trimestre de 2020”, disponible en https://www. ine.es/daco/daco42/ipv/ipv0320.pdf, 2021,

19 Véase, por ejemplo, lo señalado por BBVA RESEARCH, "Situación inmobiliaria. Diciembre 2020", disponible en file://C:/Users/c146a/Downloads/Situacion_Inmobiliaria_dic20.pdf, 2021. 


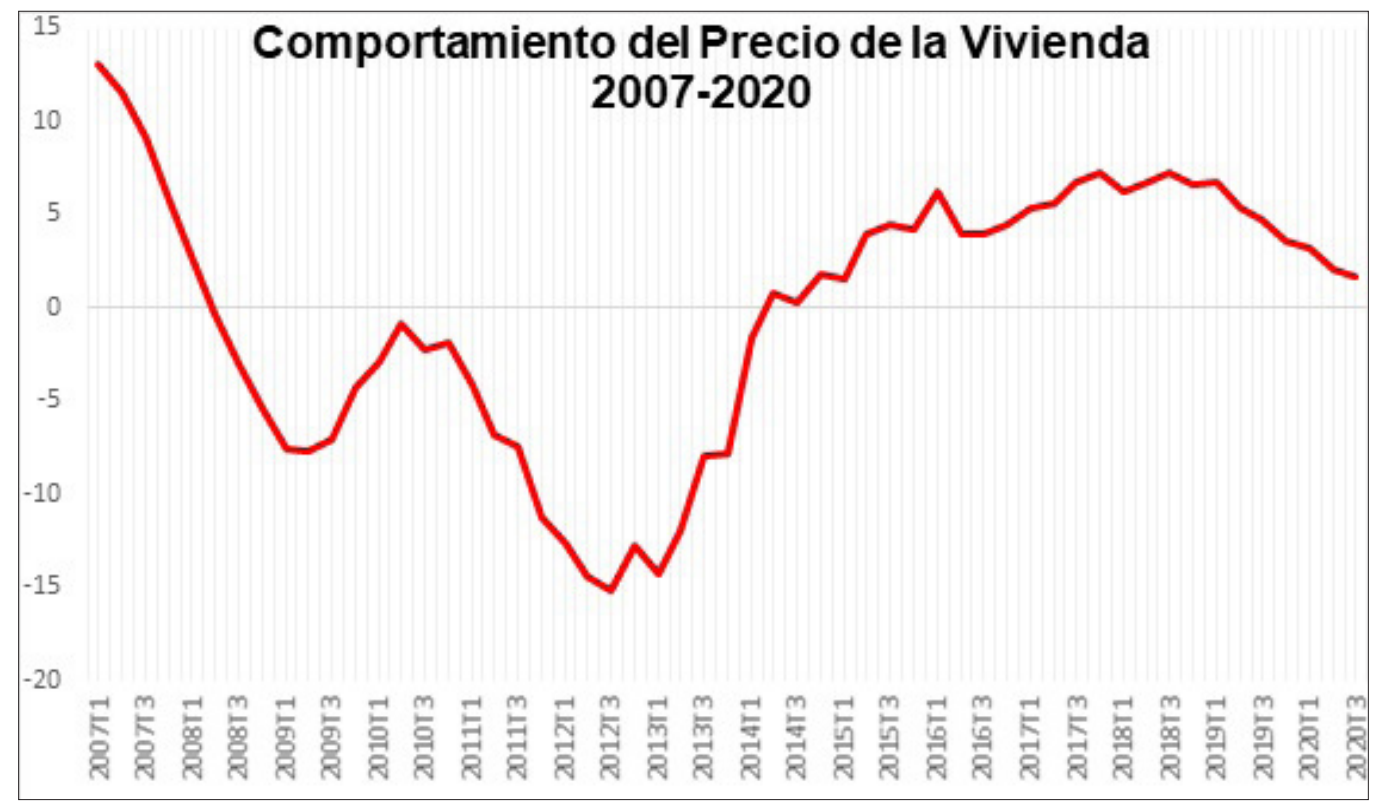

Fuente: elaboración propia a partir de INE (2021e)

La combinación de una demanda sólida y de una oferta a niveles bajos, ha ocasionado subidas en el precio de las viviendas. No obstante, frente a incrementos superiores al 6\% en 2017 y 2018, en el ejercicio 2019 se moderó hasta el 5\% y en 2020, como consecuencia de la pandemia, se espera una contención en el precio de la vivienda (muy por debajo de la contracción del PIB del 11\%), una estabilización en el primer semestre del presente ejercicio económico y una recuperación en el segundo ${ }^{20}$.

En relación al comportamiento del precio de las viviendas, son muchos los autores que esperan un efecto final moderado de la pandemia sobre los mismos, y ello porque: los vendedores están retrasando la venta de sus activos inmobiliarios antes que rebajar su precio de venta, las perspectivas a corto y medio plazo de que los tipos de interés se mantengan bajos, el hecho de que el precio de las viviendas en España sea más reducido que en otros países europeos, y por la falta de alternativas más rentables a la inversión en viviendas. ${ }^{21}$

Aunque no sea objeto de análisis en este trabajo, no podemos obviar que la evolución de los precios de la vivienda es muy dispar a lo largo del territorio nacional. De hecho, uno de los principales factores que influyen en el comportamiento del precio de este bien es la evolución de la población, por lo que aquellos territorios que presentan pérdida poblacional suelen tener un precio de la vivienda por debajo de la media nacio-

20 De acuerdo con los datos publicados por el INE, el precio de la vivienda no disminuyo durante 2020; sin embargo, otros organismos (BBVA Research, 2021, por ejemplo) sí que señalan que se produjo un descenso en el precio de las viviendas debido a la crisis sanitaria, aunque haya sido limitado en la cuantía y en el tiempo. Véase INE, “Índice de Precios de Vivienda. Tercer trimestre de 2020", disponible en https://www.ine.es/daco/daco42/ipv/ ipv0320.pdf, 2021, y BBVA RESEARCH, "Situación inmobiliaria. Diciembre 2020", disponible en file://C:/ Users/c146a/Downloads/Situacion Inmobiliaria dic20.pdf, 2021.

21 Véase, por ejemplo, OCAÑA, C. y TORRES, R., "Impacto de la pandemia sobre el sector inmobiliario", en Cuadernos de Información Económica, n² 278, pp. 14 y ss., 2020. 
nal, mientras que aquellos otros con ganancias poblacionales suelen tener un precio por encima de la media nacional. ${ }^{22}$

\subsection{Otros aspectos del mercado de la vivienda}

El primer elemento que se analiza en este apartado es el efecto que la pandemia ha tenido sobre el tiempo necesario para la venta del piso. No resulta difícil entender que, debido fundamentalmente al confinamiento, el tiempo medio de venta de un inmueble aumentó considerablemente en el ejercicio 2020. De acuerdo con varios portales inmobiliarios, se produjo un incremento del tiempo medio necesario para conseguir la venta de una vivienda de un 20\%, pasando de una demora de 5 meses en 2019 a 6 meses un año después ${ }^{23}$.

En esta variable se producen grandes disparidades territoriales, con provincias donde se tarda más de un año para realizar con éxito la transacción del bien, es el caso de provincias con muy poca población (Zamora y Teruel, por ejemplo), y otras mucho más habitadas donde la venta se realiza en un plazo de cuatro meses (Madrid y Barcelona, por ejemplo).

Otro factor que influye en el tiempo requerido para la venta de la vivienda es si esa transacción se realiza entre particulares o si se produce la intervención de un agente de la propiedad inmobiliaria. En este último caso el tiempo medio necesario para realizar la venta de la propiedad se reduce a tres meses.

Un segundo elemento que se estudia en este apartado es la influencia del coronavirus en el stock de vivienda nueva pendiente de vender. Antes de proceder a este análisis es preciso señalar que esta variable no es equiparable a vivienda vacía, pues en el stock de vivienda nueva pendiente de vender solo se contabilizan aquellas propiedades que jamás han sido transmitidas.

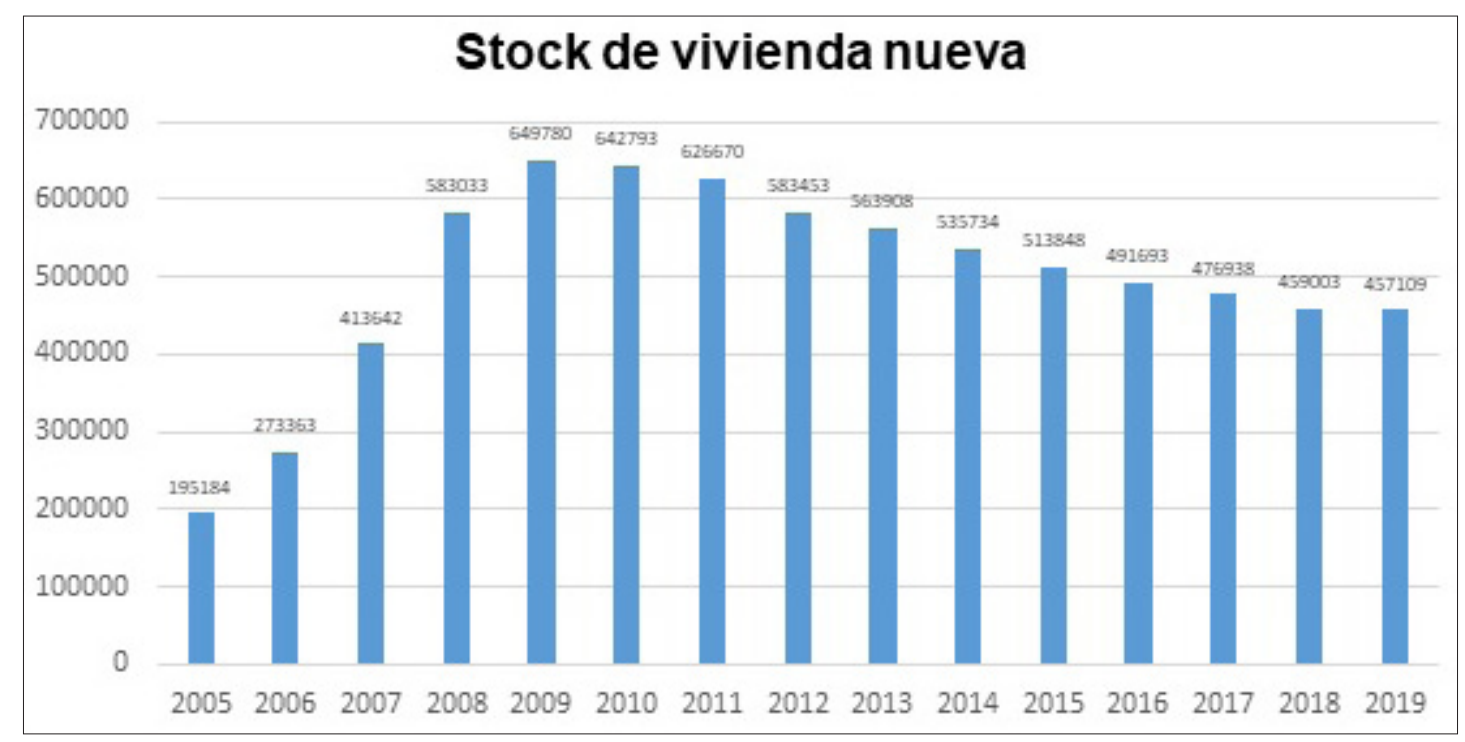

Fuente: elaboración propia a partir de Ministerio de Transportes, Movilidad y Agenda Urbana (2020a)

22 En este sentido véase el trabajo de GÓMEZ, F., "El mercado de la vivienda: diferencias territoriales en su recuperación”, Cuadernos de Información Económica, nº 274, págs.: 17-24, 2020.

23 Véase, por ejemplo, los datos publicados por IDEALISTA, "Dime dónde vives y te diré cuánto tardarás en vender tu casa ahora", disponible en https:/www.idealista.com/news/inmobiliario/vivienda/2020/11/10/787808, 2020. 
De acuerdo con los últimos datos publicados por el Ministerio de Transportes, Movilidad y Agenda Urbana, a 31 de diciembre de 2019 en España había 457.109 viviendas sin vender. En el gráfico adjunto se observa como desde el año 2009, ejercicio en el que esta variable alcanzó su máximo con casi 650 mil viviendas nuevas sin vender, hay una clara tendencia decreciente. De modo que en los últimos diez años el mercado inmobiliario ha sido capaz de absorber casi un tercio (más concretamente un 30\%) del excedente generado durante la burbuja del sector de la vivienda (desde el año 2005 al 2009 el número de viviendas nuevas sin vender aumentó casi en 455 mil unidades). No obstante, en el año 2019 el ritmo de reducción del stock se desaceleró drásticamente, hasta situarse en un $0,4 \%$ anual. ${ }^{24}$

Con los datos disponibles de los tres primeros trimestres de 2020, el número de viviendas construidas ascendió a unas 55 mil, mientras que la venta de vivienda nueva casi llegó a las 60 mil, por lo que en lo que conocemos de 2020 se aceleró el ritmo de reducción en el stock de vivienda nueva, pasando del 0,4\% en 2019 a un estimado 1,1\%. Una posible explicación a este incremento en el ritmo de absorción de la burbuja inmobiliaria este en que la pandemia ha afectado más al ritmo de construcción que al de la venta de vivienda nueva.

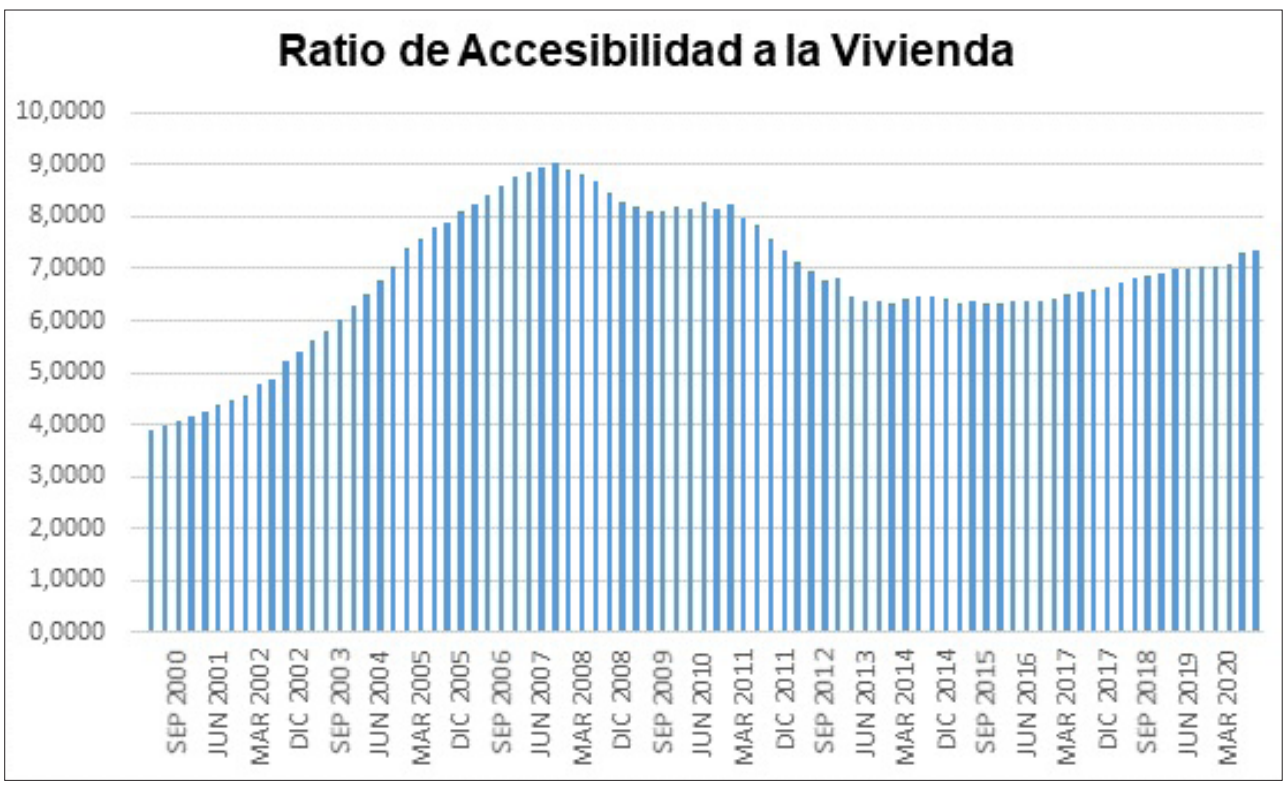

Fuente: elaboración propia a partir de Banco de España (2021a)

Para finalizar, se analiza si la crisis sanitaria de 2020 ha afectado a la accesibilidad de los españoles a la vivienda ${ }^{25}$. Con este objetivo, se trabaja con dos series estadísticas

24 Véase MINISTERIO DE TRANSPORTES, MOVILIDAD Y AGENDA URBANA, "Informe sobre el stock de vivienda nueva 2019”, disponible en https://www.mitma.gob.es/recursos_mfom/comodin/recursos/svn_19.pdf, 2020.

25 Sobre los problemas de accesibilidad a la vivienda y en relación con las aportaciones de la económica colaborativa aplicadas a la vivienda véase MUÑIZ ESPADA, E., "La nueva regulación de los contratos de crédito inmobiliario. Una ulterior evolución doctrinal hacia la vivienda colaborativa", Thomson Reuters Aranzadi, Navarra, 2018; y su contraste con el ámbito en el medio rural véase MUÑIZ ESPADA, E., "Relaciones contractuales de cooperación en el medio agrario y rural", Navarra, Aranzadi, 2020. 
elaboradas por el Banco de España: el índice de esfuerzo y la ratio de acceso a la vivienda. La primera de ellas se obtiene como el porcentaje de la renta familiar destinada a pagar las cuotas hipotecarias el primer año, mientras que la segunda, la ratio de accesibilidad, indica el número de años de renta familiar que una familia debe destinar a la compra de una vivienda y se obtiene dividiendo el precio de la vivienda por la renta familiar anual.

En los apartados anteriores se han destacado varios hechos relevantes durante la primera ola de la pandemia: el precio del bien analizado experimentó ligeros incrementos, reducción de la renta familiar como consecuencia de la evolución del mercado laboral, los tipos hipotecarios continuaron en unos niveles históricamente bajos, y problemas de escasez del bien (mayor demanda que oferta). Estos factores ayudan a entender por qué en la primera ola de la pandemia aumentó la dificultad de las familias españolas para acceder a una vivienda. Así, si se observa la evolución del esfuerzo y ratio de accesibilidad en el último año del que disponemos de datos (septiembre 2019 a septiembre de 2020), se puede concluir que incrementó la dificultad de una familia media para acceder a una vivienda: en el caso del índice de esfuerzo se pasó de un valor de 30,5\% a 31,3\%, con un aumento de casi un punto porcentual, y la ratio de acceso se incrementó de 7 a 7,3 años, retornando a valores casi olvidados de 2011 y 2014 , respectivamente. ${ }^{26}$

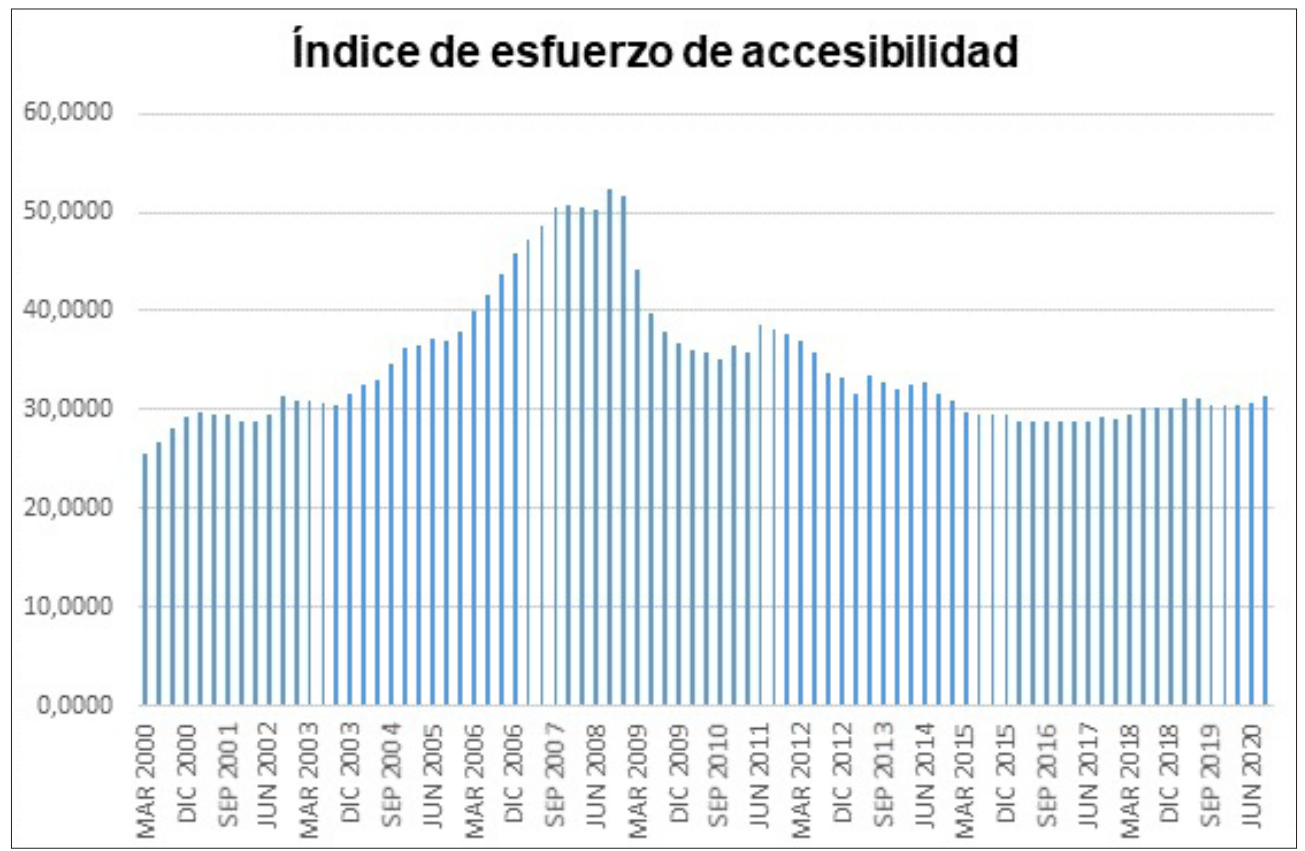

Fuente: elaboración propia a partir de Banco de España (2021a)

\section{DÓNDE ESTAMOS Y ADÓNDE VAMOS}

Se ha señalado previamente que la crisis sanitaria generada por el coronavirus ha afectado al mercado de la vivienda, pero, a diferencia de lo sucedido en la crisis económica

26 Véase también CÍRCULO DE EMPRESARIOS, "El acceso a la vivienda: un problema de oferta", disponible en https://circulodeempresarios.org/publicaciones/acceso-la-vivienda-problema-oferta/, 2020. 
de 2008, en esta ocasión el sector de la construcción y de la intermediación de viviendas no ha sido el sector económico más afectado. No obstante, la pandemia parece haber acelerado el fin del ciclo económico, pero no haberlo causado. En el ejercicio 2019 se observaba ya una tendencia decreciente en el mercado inmobiliario que el Covid-19 no ha hecho más que acelerar: las compraventas de viviendas se redujeron un $3 \%$ en 2019 y en 2020 esa reducción fue casi del 20\%; el número de visados de obra nueva presentaba una evolución negativa que la pandemia contribuyó a destacar; lo mismo cabe decir en cuanto al número de viviendas construidas, se pasó de construir unas 600 mil viviendas anuales durante los años álgidos de la crisis del 2008 a unas 55 mil en los años previos a la pandemia y durante los meses de la primera ola del coronavirus el ritmo de construcción de viviendas experimentó descensos interanuales entre el 32 y el 53\%; y en cuanto al comportamiento en el precio de este bien en los años 2018 a 2019 se aprecia una disminución en el ritmo de crecimiento de los precios, tendencia que se aceleró con el Covid-19.

La conjunción de todos esos factores durante el ejercicio 2020 (una demanda relativamente sólida, una oferta incapaz de hacerla frente, y una consiguiente subida de precios en el mercado inmobiliario) provocaron que fuera más difícil el acceso a la vivienda para una familia media española. Por lo tanto, los efectos de la crisis sanitaria generados por el Covid-19 han contribuido a que la accesibilidad a la vivienda en España se esté convirtiendo en un problema estructural de la economía española.

Para hacer frente a este problema, y teniendo en cuenta que la vivienda es un elemento esencial para la recuperación económica tras la crisis de la pandemia, fundamentalmente por su evidente capacidad para crear empleo, y que se está a la espera de la aprobación de una nueva ley de vivienda, se recogen a continuación una serie de medidas que deberían ser tenidas en cuenta por nuestros legisladores:

Desde la vertiente de la oferta: aumentar la oferta de suelo, potenciar la construcción de un parque de vivienda (social) en alquiler, simplificación y agilización de trámites administrativos, legislación que garantice la seguridad jurídica de los arrendadores, incentivos fiscales al alquiler de vivienda, mejorar la empleabilidad de los jóvenes en el sector de la construcción, etc.

Desde la vertiente de la demanda: mejoras financieras, incentivos fiscales, fomentar la colaboración público-privada, etc.

Analizado el presente, ¿qué podemos esperar del futuro más próximo? La capacidad de superación de la economía española en 2021 será la que determine la salud de nuestro sector de la vivienda.

Condicionantes favorables:

- Mejora de la economía.

- Buenas condiciones financieras.

- Efectos positivos de la vacunación.

Condicionantes desfavorables:

- Estamos inmersos en la tercera ola.

- Elevada incertidumbre. 
- Atonía en la demanda foránea (efectos del Brexit en la compraventa por parte de británicos).

En base a esos condicionantes podemos esperar una evolución negativa en la primera mitad de 2021 y una recuperación en la segunda parte del año. Ello porque la evolución de la pandemia, con el surgimiento de nuevas variantes (cepas) y la lentitud en el proceso de vacunación, incrementan la incertidumbre sobre la marcha de la economía en general y del sector inmobiliario en particular.

\section{BIBLIOGRAFÍA}

Alves, P. y Urtasun, A. "Evolución reciente del mercado de la vivienda en España”, en Boletín Económico del Banco de España, volumen 2, 2019.

Banco De España. "Informe trimestral de la economía española", Boletín Económico, 4/2020, 2021 a.

Banco De EspaÑa. "Estadísticas. Indicadores de construcción, acero y cemento", disponible en https:// www.bde.es/webbde/es/estadis/infoest/bolest23.html, 2021b.

Bbva Research. "Situación inmobiliaria. Diciembre 2020", disponible en file://C:/Users/c146a/Downloads/Situacion_Inmobiliaria_dic20.pdf, 2021a.

Bbva Research. "Situación España Primer Trimestre 2021", disponible en https://www.bbvaresearch.com/ publicaciones/situacion-espana-primer-trimestre-2021/, 2021b.

Círculo De Empresarios. "El acceso a la vivienda: un problema de oferta", disponible en https://circulodeempresarios.org/publicaciones/acceso-la-vivienda-problema-oferta/, 2020.

Colegio De Registradores De la Propiedad, Bienes Muebles Y Mercantiles De España. "Estadística registral inmobiliaria, $4^{\circ}$ trimestre 2020", disponible en hhttps://www.registradores.org/documents/33383/321222/ERI_4T_2020.pdf/ab20528b-8b4f-8b25-6ad62ff969a41568?t=1613131363018, 2021.

COMISIÓN EUROPEA. "Previsiones económicas de invierno 2021", disponible en https://ec.europa.eu/info/ sites/info/files/economy-finance/ip144_en_1.pdf, 2021.

CuAdRADO, J. R. "El sector construcción en España: análisis, perspectivas y propuestas", Colegio Libre de Eméritos, Madrid, 2010.

Felgueroso, F. Et AliA. “Aspectos económicos de la crisis del Covid-19”, en Estudios sobre la Economía Española de Fedea, n' 9, 2021.

GóMEZ, F. "El mercado de la vivienda: diferencias territoriales en su recuperación”, en Cuadernos de Información Económica, n 274, págs.: 17-24, 2020.

IDEALISTA. "Dime dónde vives y te diré cuánto tardarás en vender tu casa ahora", disponible en https://www. idealista.com/news/inmobiliario/vivienda/2020/11/10/787808, 2020.

INE. "Contabilidad Nacional Trimestral de España: principales agregados. Cuarto trimestre de 2020. Avance", disponible en https://www.ine.es/daco/daco42/daco4214/cntr0420a.pdf, 2021a.

INE. "Encuesta de Población Activa. (EPA). Cuarto trimestre de 2020", disponible en https://www.ine.es/ daco/daco42/daco4211/epa0420.pdf, 2021b.

INE. "Estadística de transmisiones de derechos de la propiedad. Diciembre 2020 y año 2020", disponible en https://www.ine.es/daco/daco42/etdp/etdp1220.pdf, 2021c.

INE. "Estadística de Hipotecas. Diciembre 2020 y año 2020", disponible en https://www.ine.es/daco/ daco42/daco426/h1220.pdf, 2021d.

INE. "Índice de Precios de Vivienda. Tercer trimestre de 2020", disponible en https://www.ine.es/daco/ daco42/ipv/ipv0320.pdf, 2021e.

INE. "Encuesta de Condiciones de Vida (ECV). Año 2019", disponible en https://www.ine.es/prensa/ ecv_2019.pdf, 2020. 
LóPEZ, M. A. "Vivienda y política pública: objetivos e instrumentos", en Documentos de Trabajo de Fedea, $\mathrm{n}^{\mathrm{o}}$ 7, 2019.

Ministerio De Transportes, Movilidad y Agenda Urbana. "Número de viviendas libres terminadas", disponible en https://apps.fomento.gob.es/BoletinOnline2/?nivel=2\&orden=32000000, 2021a.

Ministerio De Transportes, Movilidad y Agenda Urbana. "Estadística de Visados de Dirección de Obra (Estadísticas de Obras en Edificación)", disponible en https://www.fomento.gob.es/BE/?nivel $=2 \&$ orden $=09000000,2021 \mathrm{~b}$.

Ministerio De Transportes, Movilidad y Agenda Urbana. "Informe sobre el stock de vivienda nueva 2019", disponible en https://www.mitma.gob.es/recursos_mfom/comodin/recursos/svn_19.pdf, 2020a.

Ministerio De Transportes, Movilidad y Agenda Urbana. "Observatorio de vivienda y suelo. Tercer trimestre 2020", disponible en https://apps.fomento.gob.es/CVP/handlers/pdfhandler.ashx?idpub=BAW079, 2020b.

MUÑIZ, E. "Relaciones contractuales de cooperación en el medio agrario y rural", Aranzadi, 2020.

MUÑIZ, E. "La nueva regulación de los contratos de crédito inmobiliario. Una ulterior evolución doctrinal hacia la vivienda colaborativa", Thomson Reuters Aranzadi, Cizur Menor, 2018.

OCAÑA, C. y TORReS, R. "Impacto de la pandemia sobre el sector inmobiliario", en Cuadernos de Información Económica, nº 278, págs.: 11-16, 2020.

Organización Para la Cooperación y El Desarrollo Económicos (OCDE). "Perspectivas económicas. Diciembre 2020", disponible en https://www.oecd.org/perspectivas-economicas/, 2020.

Otero, M. y Blanco, J. (2014), "El sector inmobiliario en España”, Instituto de Estudios Económicos y Asprima, Madrid, 2014.

RAYA, J. M. "El impacto de la pandemia en el mercado de la vivienda en España: diagnóstico y políticas", disponible en https://dobetter.esade.edu/es/vivienda-coronavirus, 2020.

Torres, R. y Fernández, M. J. "Los rebrotes de la pandemia empeoran las expectativas económicas", en Cuadernos de Información Económica, $\mathrm{n}^{\circ}$ 278, págs.: 1-10, 2020.

Torres, R. y Fernández, M. J. "La política económica española y el Covid-19", en Cuadernos de Información Económica, $\mathrm{n}^{\circ}$ 275, págs.: 1-7, 2020. 